\title{
The Present Situation of Trichinellosis in Indochina (2001-2011)
}

\author{
Viroj Wiwanitkit ${ }^{1,2,3}$ \\ ${ }^{1}$ Wiwanitkit House, Bangkhae, Bangkok Thailand \\ ${ }^{2}$ Hainan Medical University, Hainan, China \\ ${ }^{3}$ Joseph Ayobabalola University, Nigeria
}

\begin{abstract}
Trichinellosis is an important parasitic infestation cause by round worm. This infection is considered serious and the transmission is due to eating of uncooked meat. This disease is considered an important tropical food borne infection and is sporadically reported. The sanitation seems to be an important tool for disease control. In this brief review, the author summarizes on the present situation of trichinellosis in Indochina, an important endemic area, during the present decade $(2001-2011)$.
\end{abstract}

Keywords Trichinellosis, Indochina

\section{Introduction}

Trichinellosis is an important parasitic infestation cause by round worm namely Trichinella spiralis[1]. This infection is considered serious and the transmission is due to eating of uncooked meat[1]. The infection site in human is the muscle and it can be fatal[2]. Therefore, it is considered an important tropical food borne infection[2 - 3]. Trichinellosis is sporadically reported. The sanitation seems to be an important tool for disease control. It is a basic regulation to perform trichinelloscope to detect the worm in meat before selling in the market. However, the problem is usually due to ingestion of uncontrolled meat from local production, especially the wild life meat[2-3]. The intake of wild life meat is still the common basic practice in far rural areas of developing world[2-3]. The Indochina region of Southeast Asia is a specific area of the world, which is considered tropical, that is presently attacked by several tropical parasitic infestations including to trichinellosis. In this brief review, the author summarizes on the present situation of trichinellosis in Southeast Asia, an important endemic area, during the present decade $(2001-2011)$.

\section{Method}

This work is a literature review. The methodology of this work is based on the standard literature reviewing technique. First, the author started the literature searching using the

* Corresponding author:

wviroj@yahoo.com (Viroj Wiwanitkit)

Published online at http://journal.sapub.org/fph

Copyright (C) 2012 Scientific \& Academic Publishing. All Rights Reserved standard public electronic database, PUBMED (www. pubmed.com). The inserted searching term is "trichinellosis". The period of publication in the searching is between 2001 and 2011 (the previous decade). The derived literatures that reported the situation in Indochina were further selected for further reviewing. The operative definition of "Indochina" in this report is these countries; Thailand, Laos, Myanmar and Vietnam. For each included paper, the full texts were read and the important data were extracted for summarization. The main area for summarizing in this work is the situation or the epidemiological aspect. The summary was performed using the qualitative literature review technique. The final summarized data were presented for each country in Indochina.

\section{Results}

\subsection{The Situation in Thailand}

Thailand is a country in Indochina region that trichinellosis is the disease under control. In the past, the trichinellosis outbreak could be observed in the far rural provinces. However, due to the present improvement of socioeconomic system in Thailand, the report of outbreak progressively disappears. Focusing on the recorded epidemiological data, the outbreak is most common in the northern regions, where raw and under-cooked pork and wild animals are commonly ingested[4 - 5]. Although there is no big outbreak, sporadic reports are still observed from several province of Thailand including to the province next to Bangkok, capital of Thailand[5]. Based on the summarization report by Kaewpitoon et al, "The infected patients were mostly in the 35-44 years age group and the disease occurred more frequently in men than women at a ratio of 1.7-2.0:1[5]." It can be said that the 
reduced prevalence of this disease comparing to the past might be due to the improvement of sanitation system in Thailand. However, it cannot said that there is a success in disease control since the number of reported cases is fluctuating year by year[5]. Nevertheless, there is still new concern on the trichinellosis in Thailand, the imported cases. This is a big topic in travel medicine. There are some reports on the imported trichinellosis into Thailand with the migrant workers from nearby countries[6]. Of interest, the present control program for the migrant worker in Thailand still does not cover on trichinellosis. Last but not least, although the classical trichinellosis becomes under favorable management by the public health system in Thailand, the new problem of atypical trichinellosis should be mentioned. The new infection caused by Trichinella papuae has just been seen in Thailand for a few years but there were at least two reports on the outbreaks $[7-8]$.

\subsection{The Situation in Laos}

Loas is still a developing country in Indochina that still faces up several parasitic infestations including to trichinellosis. In the remote region of Load, intake of wild life meat is still prevalent and this can contribute to the problem. However, due to the limitations of researching in Laos, there are very limited reports from this country. In the database PubMed, there are two official reports on big outbreaks of trichinellosis in Laos and all has just been reported within this decade[9 - 10]. Barennes et al. concluded that "trichinellosis may be an under-recognized but important endemic disease in Laos and reinforces the need to urgently implement veterinary and educational programs[10].” Nevertheless, it is believed that the problem is still required management in this country. The imported infection from Laos to other countries can be seen and implies the existence of problem in Laos[6, 11].

\subsection{The Situation in Myanmar}

Myanmar is another country in Indochina that several parasitic infestations are common. The public health improvement within this country is still required. There are extremely limited reports from this country due to the current political situation in Myanmar. However, it is confirmed that the animal meat in this country is still risk for containing parasite[12].

\subsection{The Situation in Vietnam}

Of interest, although Vietnam lies in Indochina similar to Thailand, Loas and Myanmar, the problem of trichinellosis in this country is not much. The survey on the meat in Vietnam still shows the contamination of the parasite[13]. The eating style, which tends to eat cooked food, might be the clue for the observation. Based on the literature search, there is only 1 report of outbreak from Vietnam due to eating raw pork[14]. Although there is not evidence, it can be said that trichinellosis is still presently existed in Vietnam and it is still the problem to be managed.

\section{Discussion}

According to the literature searching, there are few publications [4 - 14] focusing on the situation of trichinellosis in Indochina, during the present decade $(2001-2011)$. The possible reasons can be a) there is no new disease in this area, b) the disease has been neglected and c) the disease is existed and still public health concern but there is a poor literature reporting system from this area.

Indeed, the problem is still existed in the remote area of Indochina, which is still considered the developing region of the world. The existed of the problem calls for the needs for good management in the health system in this area. Indeed, the food borne infectious disease in Indochina is still common and problematic at present[3]. However, due to the limitation of resource, unstable political situation in many countries and the lack of experts in Indochina, the limitation of the standard disease, disease management, researching and publication activity can be expected.

Based on the existed data, sporadic outbreaks can be seen and the original source is still the poor controlled animals' flesh. The outbreaks usually occur in the far provincial areas. The problem of food sanitation in the underprivileged communities is still the urgent requirement. How to manage the deep root belief in intake of uncooked and poorly cooked food is the big challenge.

To reach the success in disease management, the multidisciplinary approach with the community participation must be the key factor[15-16]. Not only trichinellosis but also other food borne diseases have to be managed at the same time.

\section{Conclusions}

The problem of trichinellosis is still present in Indochina in the present decade despite the improvement of sanitation in this area. The good sanitation and food control system has to be improved. This infection is still be the important public health to be considered of this region.

\section{REFERENCES}

[1] Wang ZQ, Cui J. Diagnosis and treatment of trichinellosis. Zhongguo Ji Sheng Chong Xue Yu Ji Sheng Chong Bing Za Zhi. 2008 Feb 28;26(1):53-7

[2] Dupouy-Camet J, Kociecka W, Bruschi F, Bolas-Fernandez F, Pozio E. Opinion on the diagnosis and treatment of human trichinellosis. Expert Opin Pharmacother. 2002 Aug; 3(8): 1117-30

[3] Wiwanitkit V. Focus on Emerging Food-Borne Infections. New York: Nova Publisher, 2009

[4] Kaewpitoon N, Kaewpitoon SJ, Pengsaa P. Food-borne parasitic zoonosis: distribution of trichinosis in Thailand. World J Gastroenterol. 2008 Jun 14;14(22):3471-5 
[5] Kaewpitoon N, Kaewpitoon SJ, Philasri C, Leksomboon R, Maneenin C, Sirilaph S, Pengsaa P. Trichinosis: epidemiology in Thailand. World J Gastroenterol. 2006 Oct 28;12 (40):6440-5

[6] Suwansrinon K, Wilde H, Burford B, Hanvesakul R, Sitprija V. Human trichinellosis from Laos. J Travel Med. 2007 Jul-Aug;14(4):274-7

[7] Khumjui C, Choomkasien P, Dekumyoy P, Kusolsuk T, Kongkaew W, Chalamaat M, Jones JL. Outbreak of trichinellosis caused by Trichinella papuae, Thailand, 2006. Emerg Infect Dis. 2008 Dec;14(12):1913-5

[8] Kusolsuk T, Kamonrattanakun S, Wesanonthawech A, Dekumyoy P, Thaenkham U, Yoonuan T, Nuamtanong S, SaNguankiat S, Pubampen S, Maipanich W, Panitchakit J, Marucci G, Pozio E, Waikagul J. The second outbreak of trichinellosis caused by Trichinella papuae in Thailand. Trans R Soc Trop Med Hyg. 2010 Jun;104(6):433-7

[9] Sayasone S, Odermatt P, Vongphrachanh P, Keoluangkot V, Dupouy-Camet J, Newton PN, Strobel M. A trichinellosis outbreak in Borikhamxay Province, Lao PDR. Trans R Soc Trop Med Hyg. 2006 Dec;100(12):1126-9

[10] Barennes H, Sayasone S, Odermatt P, De Bruyne A, Hongsakhone S, Newton PN, Vongphrachanh P, Martinez-Aussel B, Strobel M, Dupouy-Camet J. A major trichinellosis outbreak suggesting a high endemicity of Trichinella infection in northern Laos. Am J Trop Med Hyg. 2008 Jan;78(1):40-4

[11] Cui J, Wang ZQ, Xu BL. The epidemiology of human trichinellosis in China during 2004-2009. Acta Trop. 2011 Apr;118(1):1-5

[12] Pozio E. Taxonomy of Trichinella and the epidemiology of infection in the Southeast Asia and Australian regions. Southeast Asian J Trop Med Public Health. 2001;32 Suppl 2:129-32

[13] Vu Thi N, Dorny P, La Rosa G, To Long T, Nguyen Van C, Pozio E. High prevalence of anti-Trichinella IgG in domestic pigs of the Son La province, Vietnam. Vet Parasitol. $2010 \mathrm{Feb}$ 26;168(1-2):136-40

[14] Taylor WR, Tran GV, Nguyen TQ, Dang DV, Nguyen VK, Nguyen CT, Nguyen LT, Luong CQ, Scott T, Dang TC, Tran TH, Nguyen TD, Pham KT, Fox A, Horby P, Wertheim H, Doan HN, Nguyen HH, Trinh LM, Nguyen TV, Nguyen KV, Nguyen DH. Acute febrile myalgia in Vietnam due to trichinellosis following the consumption of raw pork. Clin Infect Dis. 2009 Oct 1;49(7):e79-83

[15] Todd EC. Epidemiology of foodborne diseases: a worldwide review. World Health Stat Q. 1997;50(1-2):30-50

[16] Greig JD, Ravel A. Analysis of foodborne outbreak data reported internationally for source attribution. Int $\mathrm{J}$ Food Microbiol. 2009 Mar 31;130(2):77-87 